\title{
Alternative Formula for the Series of Consecutive $m$-Squares under Alternating Signs
}

\author{
Leomarich F. Casinillo ${ }^{1 *}$ and Leo A. Mamolo ${ }^{2}$ \\ ${ }^{1}$ Department of Mathematics and Physics \\ 2Department of Teacher Education \\ Visayas State University \\ Visca, Baybay City, Leyte, Philippines \\ Email: ${ }^{*}$ leomarich casinillo@yahoo.com, ${ }^{2 l e o m a m o l o @ g m a i l . c o m ~}$
}

\begin{abstract}
This paper developed a simple but elegant formula for the series of consecutive square of natural numbers under alternating signs. Furthermore, this study investigated the said formula under odd and even number of terms and discuss some important results.
\end{abstract}

Keywords: consecutive $m$-squares; alternating signs; odd and even terms.

\begin{abstract}
Abstrak
Dalam paper ini kita membangun formula yang sederhana namun elegan untuk menghitung jumlah deret berganti-tanda dari kuadrat bilangan-bilangan asli berurutan. Kita akan menyelidiki formula untuk kasus banyaknya suku ganjil maupun genap dan mendiskusikan beberapa hasil yang penting.

Kata kunci: $m$-kuadrat berurutan; berganti-tanda; bersuku ganjil dan bersuku genap.
\end{abstract}

\section{INTRODUCTION}

In the study of number theory and combinatorics, a lot of mathematicians have been interested in finding the sums of powers of positive integers [1] [2] [3] [4]. Through the years of various pursuits, they have given formulas for the sum of the first $n$ positive integers,

$$
1+2+\cdots+n=\frac{n(n+1)}{2}
$$

the sum of the squares of the first $n$ positive integers,

$$
1^{2}+2^{2}+\cdots+n^{3}=\frac{n(n+1)(2 n+1)}{6},
$$

and so on. This formulas can be proven using mathematical induction. In 1631, Faulhaber expresses the sum of the $p^{t h}$ powers of the first $n$ positive integer $1^{p}+2^{p}+\cdots+n^{p}$, as a $(p+1)^{t h}$-degree polynomial function of $n$ up to the $17^{\text {th }}$ power [4]. And this polynomial can be expressed by Bernoulli numbers [3] [4]. In this study, we are concern with the sum of the squares of the first $t$ positive integers. But our investigation put some effort on the sum of consecutive $m$-squares given alternating 
signs of quadratic polynomial in $n$. Let $n$ and $m$ be a positive integer and $S_{t}(n, m)$ be a series of square of the consecutive positive integer with alternating sign, that is,

if $m \equiv 0(\bmod 2)$ and $t=2 n-1$, also we have

$$
S_{t}^{o}(n, m)=\sum_{j=m}^{m+2 n-2}(-1)^{j} j^{2},
$$

$$
S_{t}^{o}(n, m)=\sum_{j=m}^{m+2 n-2}(-1)^{j+1} j^{2},
$$

if $m \equiv 1(\bmod 2)$ and $t=2 n-1$. Now, considering that $t \equiv 0(\bmod 2)$, then we have

$$
S_{t}^{e}(n, m)=\sum_{j=m}^{m+2 n-1}(-1)^{j} j^{2},
$$

if $m \equiv 0(\bmod 2)$ and $t=2 n$. And also we obtained

$$
S_{t}^{e}(n, m)=\sum_{j=m}^{m+2 n-1}(-1)^{j+1} j^{2}
$$

if $m \equiv 1(\bmod 2)$ and $t=2 n$. In general, $S_{t}(n, m)$ is a family of quadratic polynomial in $n$ and $m$. The positive integer $t$ in the series is the number of terms which is a function of natural number $n$ and $m$ is the initial positive integer in the series, that is, $m^{2}$ is the first term. In literature, there are some researchers use this series for scientific applications [5] [6]. In this paper, we developed a simple formula for the sum of consecutive $m$-square under alternating signs which is a function of positive integer $n$. The purpose of this study is to develop an explicit form to calculate the two series $S_{t}^{o}(n, m)$ and $S_{t}^{e}(n, m)$ in a convenient way.

\section{RESULTS}

The following result is immediate from the definitions above when $t \equiv 1(\bmod 2)$.

Theorem 1. Let $n$ and $m$ be positive integers. If $n=\frac{t+1}{2}$ where $t \equiv 1(\bmod 2)$, then

$$
S_{t}^{o}(n, m)=2 n^{2}+(2 m-3) n+(m-1)^{2}>0 \text {. }
$$

Proof: We suppose that $t$ is odd and it implies that $t=2 n-1$, where $n$ is a positive integer. Then, there are $(t+1) / 2$ positive terms and $(t-1) / 2$ negative terms in the series $S_{t}^{o}(n, m)$ by definition. It is clear that the sum of positive terms is greater than the absolute value of the sum of negative terms. Hence, it follows that $S_{t}^{o}(n, m)>0$ for all positive integer $m$. Now, since $S_{t}^{o}(n, m)$ is quadratic polynomial in nature by definition, then we suppose that $S_{t}^{o}(n, m)=a n^{2}+b n+c$, where $a=$ $\mu_{1}(m), b=\mu_{2}(m)$ and $c=\mu_{3}(m)$ are positive integers and function of positive integer $m$. Then, we solve for the parameters $a, b$ and $c$ by simulation. If $n=1$, then $t=1$ and we have

$$
S_{1}^{o}(1, m)=a+b+c=m^{2} .
$$

If $n=2$, then $t=3$ and it implies that

$$
S_{3}^{o}(2, m)=4 a+2 b+c=m^{2}-(m+1)^{2}+(m+2)^{2}
$$

and if $n=3$, then $t=5$ and we obtained,

$$
S_{5}^{o}(3, m)=9 a+3 b+c=m^{2}-(m+1)^{2}+(m+2)^{2}-(m+3)^{2}+(m+4)^{2} .
$$

We get the difference between (8) and (9), we obtained the following

$$
S_{3}^{o}(2, m)-S_{1}^{o}(1, m)=3 a+b=2 m+3 .
$$

Also we get the difference of equation (9) and (10), so we have

$$
S_{5}^{o}(3, m)-S_{3}^{o}(2, m)=5 a+b=2 m+7 .
$$

Finally, we get the difference between (11) and (12). And this implies that $a=2$. By substituting $a=$ 2 in equation (11) or (12), we get $b=2 m-3$. Further, substituting $a=2$ and $b=2 m-3$ to equation (8) and it follows that $c=m^{2}-2 m+1=(m-1)^{2}$. Thus, for $t \equiv 1(\bmod 2)$, we end up with 
$S_{t}^{o}(n, m)=2 n^{2}+(2 m-3) n+(m-1)^{2}$ for all positive integers $n$ and $m$. This completes the proof.

The next proof for Theorem 1 is an alternative method using the mathematical induction. The method of induction verifies that the above equation (7) is true for all positive integer $n$.

Proof (Mathematical induction): In this case $P(n)$ is the statement

$$
m^{2}-(m+1)^{2}+(m+2)^{2}-\cdots+(m+2 n-2)^{2}=2 n^{2}+(2 m-3) n+(m-1)^{2},
$$

where $t=2 n-1$. Now, consider the base case $P(1)$ :

$$
\begin{aligned}
& m^{2}=2(1)^{2}+(2 m-3)(1)+(m-1)^{2} \\
& m^{2}=m^{2} .
\end{aligned}
$$

Therefore, $P(1)$ is true. Our induction hypothesis is given by the statement $P(n)$. Finally, we want to show that $P(n+1)$ is also true. Without loss of generality, let $m \equiv 0(\bmod 2)$, then

$$
\begin{aligned}
S_{t+2}^{o}(n+1, m) & =\sum_{j=m}^{m+2 n-2}(-1)^{j} j^{2}-(m+2 n-1)^{2}+(m+2 n)^{2} \\
& =2 n^{2}+(2 m-3) n+(m-1)^{2}-(m+2 n-1)^{2}+(m+2 n)^{2} .
\end{aligned}
$$

By simplifying the equation (17), then we have

$$
\begin{aligned}
S_{t+2}^{o}(n+1, m) & =2 n^{2}+(2 m+1) n+m^{2} \\
& =2 n^{2}+(2 m-3+4) n+(m-1)^{2}+(2 m-1) \\
& =2 n^{2}+4 n+2+2 m n+2 m-3 n-3+(m-1)^{2} \\
& =2(n+1)^{2}+(2 m-3)(n+1)+(m-1)^{2} .
\end{aligned}
$$

Thus, this completes the proof showing that $P(n)$ is true for all positive integer $n$.

To illustrate this series more clearly, the following Table 1 shows the values of $S_{t}^{o}(n, m)$ when $t \equiv 1(\bmod 2)$ for $n, m \in\{1,2,3, \ldots, 10\}$.

Table 1. Distribution of values of $S_{t}^{o}(n, m)$ when $t \equiv 1(\bmod 2)$ for $n, m \in\{1,2,3, \ldots, 10\}$.

\begin{tabular}{ccccccccccc}
$\begin{array}{c}\mathbf{n}_{\boldsymbol{n}}^{\mathbf{m}} \\
\mathbf{1}\end{array}$ & $\mathbf{1}$ & $\mathbf{2}$ & $\mathbf{3}$ & $\mathbf{4}$ & $\mathbf{5}$ & $\mathbf{6}$ & $\mathbf{7}$ & $\mathbf{8}$ & $\mathbf{9}$ & $\mathbf{1 0}$ \\
\hline $\mathbf{2}$ & 6 & 4 & 9 & 16 & 25 & 36 & 49 & 64 & 81 & 100 \\
\hline $\mathbf{3}$ & 15 & 22 & 18 & 27 & 38 & 51 & 66 & 83 & 102 & 123 \\
\hline $\mathbf{4}$ & 28 & 37 & 48 & 61 & 55 & 70 & 87 & 106 & 127 & 150 \\
\hline $\mathbf{5}$ & 45 & 56 & 69 & 84 & 101 & 120 & 141 & 164 & 189 & 216 \\
\hline $\mathbf{6}$ & 66 & 79 & 94 & 111 & 130 & 151 & 174 & 199 & 226 & 255 \\
\hline $\mathbf{7}$ & 91 & 106 & 123 & 142 & 163 & 186 & 211 & 238 & 267 & 298 \\
\hline $\mathbf{8}$ & 120 & 137 & 156 & 177 & 200 & 225 & 252 & 281 & 312 & 345 \\
\hline $\mathbf{9}$ & 153 & 172 & 193 & 216 & 241 & 268 & 297 & 328 & 361 & 396 \\
\hline $\mathbf{1 0}$ & 190 & 211 & 234 & 259 & 286 & 315 & 346 & 379 & 414 & 451 \\
\hline
\end{tabular}

The next result is a quick consequence from the definitions above when $t \equiv 0(\bmod 2)$.

Theorem 2. Let $n$ and $m$ be positive integers. If $n=\frac{t}{2}$ where $t \equiv 0(\bmod 2)$, then

$$
S_{t}^{e}(n, m)=-2 n^{2}-(2 m-1) n<0 .
$$

Proof: Now, we suppose that $t$ is even and it simply follows that $t=2 n$, for positive integer $n$. By definition, the series $S_{t}^{e}(n, m)$ has $t / 2$ positive terms and $t / 2$ negative terms. Note that the first sign 
in the series is positive, then the sum of the absolute value of negative terms is greater than the sum of the positive terms. Hence, $S_{t}^{e}(n, m)<0$, for all positive integer $m$. Again, by definition, $S_{t}^{e}(n, m)$ is quadratic polynomial in nature as a function of positive integer $n$. So, we suppose that $S_{t}^{e}(n, m)=$ $a n^{2}+b n+c$, where $a=\mu_{1}(m), b=\mu_{2}(m)$ and $c=\mu_{3}(m)$ are positive integers and function of positive integer $m$. So, by simulation we can solve for the parameters $a, b$ and $c$. If we let $n=1$, then we obtained $t=2$ and we have

$$
S_{2}^{e}(1, m)=a+b+c=m^{2}-(m+1)^{2} .
$$

If $n=2$, then $t=4$ and it follows that

$$
S_{4}^{e}(2, m)=4 a+2 b+c=m^{2}-(m+1)^{2}+(m+2)^{2}-(m+3)^{2} .
$$

Lastly, if $n=3$, then $t=6$ and we obtained,

$$
S_{6}^{e}(3, m)=9 a+3 b+c=m^{2}-(m+1)^{2}+(m+2)^{2}-(m+3)^{2}+(m+4)^{2}-(m+5)^{2} .
$$

Then we get the difference between (23) and (24), and it follows that

$$
S_{4}^{e}(2, m)-S_{2}^{e}(1, m)=3 a+b=-2 m-5
$$

Getting the difference between that equations (24) and (25), we obtained the following

$$
S_{6}^{e}(3, m)-S_{4}^{e}(2, m)=5 a+b=-2 m-9 .
$$

Finally, we get the difference between (26) and (27), and this follows that $a=-2$. Then, by substituting $a=-2$ to equation (26) or (27) we obtained $b=-2 m+1$. Substituting $a=-2$ and $b=$ $-2 m+1$, to equation $(22)$ we arrived with $c=0$. Thus, if $t \equiv 0(\bmod 2)$, then it implies that $S_{t}^{e}(n, m)=-2 n^{2}-(2 m-1) n$, for all positive integers $n$ and $m$. And this completes the proof.

The following alternative proof is the method of mathematical induction, Theorem 2 is shown to be true for all positive integer $n$.

Proof (Mathematical induction): Let $A(n)$ is the statement

$$
m^{2}-(m+1)^{2}+(m+2)^{2}-\cdots-(m+2 n-2)^{2}=-2 n^{2}-(2 m-1) n,
$$

where $t=2 n$. Let us consider the base case $A(1)$, so we obtained

$$
\begin{gathered}
m^{2}-(m+1)^{2}=-2(1)^{2}-(2 m-1)(1) \\
m^{2}-(m+1)^{2}=m^{2}-(m+1)^{2} .
\end{gathered}
$$

Hence, it implies that $A(1)$ is true. So, the induction hypothesis is given by the statement $A(n)$. Lastly, we show that $A(n+1)$ is true. Without loss of generality, let $m \equiv 0(\bmod 2)$, then it immediately follows that

$$
\begin{aligned}
S_{t+2}^{e}(n+1, m) & =\sum_{j=m}^{m+2 n-1}(-1)^{j} j^{2}+(m+2 n)^{2}-(m+2 n+1)^{2} \\
& =-2 n^{2}-(2 m-1) n+(m+2 n)^{2}-(m+2 n+1)^{2} .
\end{aligned}
$$

Simplifying and manipulating equation (32) above, we obtained

$$
\begin{aligned}
S_{t+2}^{e}(n+1, m) & =-2 n^{2}-2 m n-2 m-3 n-1 \\
& =-2 n^{2}-4 n-2-2 m n-2 m+n+1 \\
& =-2\left(n^{2}+2 n+1\right)-[2 m n+2 m-n-1] \\
& =-2(n+1)^{2}-(2 m-1)(n+1) .
\end{aligned}
$$

Thus, the proof is complete showing that $A(n)$ is true for all positive integer $n$.

Again, to illustrate this clearly, the following Table 2 shows the distribution of values of $S_{t}^{e}(n, m)$ when $t \equiv 0(\bmod 2)$ for $n, m \in\{1,2,3, \ldots, 10\}$. 
Alternative Formula for the Series of Consecutive $m$-Squares under Alternating Signs

Table 2. Distribution of values of $S_{t}^{e}(n, m)$ when $t \equiv 0(\bmod 2)$ for $n, m \in\{1,2,3, \ldots, 10\}$.

\begin{tabular}{ccccccccccc}
\hline $\begin{array}{r}\boldsymbol{m} \\
\boldsymbol{n}\end{array}$ & $\mathbf{1}$ & $\mathbf{2}$ & $\mathbf{3}$ & $\mathbf{4}$ & $\mathbf{5}$ & $\mathbf{6}$ & $\mathbf{7}$ & $\mathbf{8}$ & $\mathbf{9}$ & $\mathbf{1 0}$ \\
\hline $\mathbf{1}$ & -3 & -5 & -7 & -9 & -11 & -13 & -15 & -17 & -19 & -21 \\
\hline $\mathbf{2}$ & -10 & -14 & -18 & -22 & -26 & -30 & -34 & -38 & -42 & -46 \\
\hline $\mathbf{3}$ & -21 & -27 & -33 & -39 & -45 & -51 & -57 & -63 & -69 & -75 \\
\hline $\mathbf{4}$ & -36 & -44 & -52 & -60 & -68 & -76 & -84 & -92 & -100 & -108 \\
\hline $\mathbf{5}$ & -55 & -65 & -75 & -85 & -95 & -105 & -115 & -125 & -135 & -145 \\
\hline $\mathbf{6}$ & -78 & -90 & -102 & -114 & -126 & -138 & -150 & -162 & -174 & -186 \\
\hline $\mathbf{7}$ & -105 & -119 & -133 & -147 & -161 & -175 & -189 & -203 & -217 & -231 \\
\hline $\mathbf{8}$ & -136 & -152 & -168 & -184 & -200 & -216 & -232 & -248 & -264 & -280 \\
\hline $\mathbf{9}$ & -171 & -189 & -207 & -225 & -243 & -261 & -279 & -297 & -315 & -333 \\
\hline $\mathbf{1 0}$ & -210 & -230 & -250 & -270 & -290 & -310 & -330 & -350 & -370 & -390 \\
\hline
\end{tabular}

The following corollaries are direct consequences from Theorem 1 and 2 .

Corollary 3. For any positive integers $t$ and $n$, the following holds true:
i. $\quad S_{t}^{o}(n, 1) \equiv 0(\bmod n)$ and $S_{t}^{e}(n, 1) \equiv 0(\bmod n)$,
ii. $\quad S_{t}^{o}(n, 1) \equiv 0(\bmod t)$ and $S_{t}^{e}(n, 1) \equiv 0(\bmod t)$.

Corollary 4. For any positive integers $m$ and $n$, the following holds true:

i. $\quad S_{t}^{o}(n, m) \equiv 1(\bmod 2)$ and $S_{t}^{e}(n, m) \equiv 1(\bmod 2) \quad$ whenever $n$ is odd; and

ii. $\quad S_{t}^{o}(n, m) \equiv 0(\bmod 2)$ and $S_{t}^{e}(n, m) \equiv 0(\bmod 2) \quad$ whenever $n$ is even; where $t=2 n-1$ or $t=2 n$.

\section{CONCLUSION}

In this paper, we have developed a new formula for the series of $n$ consecutive square of natural numbers under alternating signs. The formula constructed is in the form of a quadratic polynomial which is a function of $n$ and $m$, where $n$ and $m$ are a natural number. Further, it is concluded that the said series with odd term and even term have positive and negative values, respectively, i.e., $S_{t}^{o}(n, m)>0$ and $S_{t}^{e}(n, m)<0$. In future research, one may consider a series of consecutive numbers with the power of rational numbers. It would also be interesting if this series is under alternating signs.

\section{REFERENCES}

[1] R. P. Bambah and S. Chowla, "On numbers which can be express as a sum of two squares.," Pro. Nat. Acad. Sci. India, vol. 13, pp. 101-103, 1947.

[2] G. Harman, "Sums of two squares in short intervals," Proceeding of London Mathematical Society, vol. 6, pp. 225-241, 1991.

[3] F. T. Howard, "Sums of powers of integers via generating functions," Fibonacci Quarterly, vol. 34, pp. 244-256, 1996. Retrieved from https://www.fq.math.ca/Scanned/34-3/howard.pdf.

[4] M. Merca, "An alternative to Faulhaber's formula," The American Mathematical Monthly, vol. 122, no. 6, pp. 599-601, 2014. DOI: 10.4169/amer.math.monthly.122.6.599. 
[5] M. Marin, "Contributions on Uniqueness in thermoelastodynamics on bodies with voids," Ciencias Mathematicas (Havana), vol. 16, no. 2, pp. 101-109, 1998.

[6] M. Marin, "An evolutionary equation in thermoelasticity of dipolar bodies," Journal of Mathematical Physics, vol. 40, no. 3, pp. 1391-1399, 1999. 